\title{
TNF-Related Apoptosis-Inducing Ligand Death Pathway-Mediated Human Beta-Cell Destruction
}

\author{
D. Ou ${ }^{1}$, D.L. Metzger ${ }^{1}$, X. Wang $^{1}$, J. Huang ${ }^{1}$, P. Pozzilli ${ }^{2}$, A.J. Tingle ${ }^{1}$ \\ ${ }^{1}$ Department of Pediatrics, University of British Columbia, British Columbia, Canada \\ ${ }^{2}$ Department of Diabetes, St. Bartholomew's Hospital, Royal London School of Medicine, London, UK
}

\section{Abstract}

Aims/hypothesis. The aim of this study is to investigate whether apoptosis in human beta cells can be related to the induction of the tumor necrosis factorrelated apoptosis-inducing ligand (TRAIL) pathway.

Methods. We examined the expression of TRAIL and TRAIL receptors in two human pancreatic beta-cell lines and in human primary islet cells using RT-PCR assays and flow cytometric analyses and tested TRAIL-mediated beta-cell destruction in ${ }^{51} \mathrm{Cr}$ release cytotoxicity assays, Annexin-V and APO-DIREC assays.

Results. Most of the human beta cells express TRAIL receptors-R1, -R2, -R3, -R4 and/or TRAIL. TRAIL induced much stronger cytotoxicity and apoptosis to beta-cell lines CM and HP62 than did FasL, TNF- $\alpha$, LT $\alpha 1 \beta 2$, LT $\alpha 2 \beta 1$, LIGHT, and IFN- $\gamma$. The cytotoxicity and apoptosis induced by TRAIL to beta-cell lines CM were inhibited competitively by soluble TRAIL receptors, R1, R2, R3 or R4. Treatment of these beta cells with antibodies against TRAIL receptors was able to block the cytotoxicity of TRAIL to these cells. Beta-cell antigen-specific CTL $\left(\mathrm{CD}^{+}{ }^{+}\right.$and $\mathrm{CD}^{+}$) clones express TRAIL, suggesting that these cells are potential sources of TRAIL-inducing betacell destruction. Normal primary islet cells from most donors are resistant to the cytotoxicity mediated by TRAIL. However, treatment with an inhibitor of protein synthesis (cycloheximide) or with an enzyme (PI-PLC) that can remove TRAIL-R3 from the isletcell membrane was able to increase the susceptibility of TRAIL-resistant primary islet cells to the TRAIL death pathway.

Conclusion/interpretation. The TRAIL death pathway is present and can function in human islet beta cells, but unidentified inhibitors of the TRAIL death pathway are present in normal islet cells. [Diabetologia (2002) 45:1678-1688]

Keywords Type I diabetes, TRAIL, apoptosis, cytotoxicity, pancreatic beta cells.
Received: 21 March 2002 / Revised: 24 June 2002

Published online: 23 October 2002

C) Springer-Verlag 2002

Corresponding author: Dr. Dawei Ou, Department of Pediatrics, Faculty of Medicine, The University of British Columbia, 950 West 28th Avenue, Vancouver, B.C. Canada, V5Z 4H4. E-mail: daweiou@interchange.ubc.ca

Abbreviations: CHX, Cycloheximide; CTL, cytotoxic T lymphocyte; FasL, Fas ligand; INSB, insulin $\beta$ chain; mAb, monoclonal antibody; LT, lymphotoxin; NBC, naive beta cells; NOD, non-obese diabetic; PBMC, peripheral blood mononuclear cells; PHA, phytohemagglutinin; PI-PLC, phosphatidylinositol-specific phospholipase C; rIL-2, recombinant IL-2; TCR, T-cell receptor; TRAIL, TNF-related apoptosis-inducing ligand.
The majority of cases of Type I (insulin-dependent) diabetes mellitus are caused by progressive loss of insulin-producing beta cells and are generally believed to result from $\mathrm{T}$ cell-mediated multiple death pathways [1]. Programmed cell death, or apoptosis is an important pathogenesis in the development of Type I diabetes [1, 2, 3]. Morphological changes indicative of apoptosis have been observed in normal islets and appear at an increased frequency in islets with Type I diabetes-associated insulitis [3]. Defining the signalling components of apoptosis present in beta cells is important because it could provide insights into potential pathogenic mechanisms and might lead to the development of pharmacological interventions for the treat- 
ment of Type I diabetes. Several apoptosis signalling pathways, initiated by death receptor ligands such as Fas ligand (FasL) and TNF- $\alpha$ have been shown to be active in mouse islet beta cells and could be involved in destructive insulitis $[4,5,6,7]$. TRAIL (also known as Apo2 ligand) is a $40-\mathrm{kDa}$ type II transmembrane protein that is structurally related to the TNF family of proteins including TNF- $\alpha$ and FasL [8, 9]. TRAIL, like TNF- $\alpha$ and FasL, has both membrane-bound and soluble forms [8] and acts via type 1 membrane receptors that signal apoptosis through a cytoplasmic death domain $[8,9,10]$. The extracellular domain of TRAIL shares the highest amino acid homology with the Fas ligand (28\%), TNF- $\alpha$ (23\%), lymphotoxin (LT)- $\alpha$ $(23 \%)$, and LT- $\beta(22 \%)[8,9]$. To date, several TRAIL receptors have been identified. Two of these receptors TRAIL-R1/death receptor 4 (DR4) and TRAIL-R2/ death receptor 5 (DR5) contain cytoplasmic death domains and signal apoptosis through a caspase-dependent pathway [11, 12, 13, 14]. Engagement of either of these two receptors by TRAIL results in the recruitment and activation of caspase-8, as well as cleavage of BH3-interacting death domain agonist and cytochrome $c$ release from mitochondria. These events that subsequently lead to the activation of the caspase cascade $[8,15,16]$. In contrast with TRAIL-R1 and TRAIL-R2, TRAIL-R3/decoy receptor (DcR) 1 exists as a glycosyl-phosphatidylinositol-anchored surface protein that is not able to signal cell death, thus acting as a decoy receptor $[11,13,15,16,17,18,19]$. A fourth TRAIL receptor, TRAIL-R4/DcR2, contains only a partial death domain and does not mediate apoptosis upon binding of TRAIL. Transfection of nonsignalling TRAIL-R3 or TRAIL-R4 results in a down-regulation in the amount of cell death. TRAIL-R3 and TRAIL-R4 both act as decoy receptors and dominant-negative inhibitors of TRAIL-induced death $[11,13,20]$. The TRAIL pathway can induce apoptosis in a wide range of transformed tumor cells and virus-infected cells as well as normal human hepatocytes and brain cells $[21,22]$. A recent study showed that TRAIL pathway mediated early isolated normal islet apoptosis and inhibition of the TRAIL pathway might improve isolated islet survival and reduce functional islet mass loss [23]. However, little is known about the roles played by the TRAIL death pathway on beta-cell destruction in Type I diabetes. Recently, pancreatic beta-cell "fratricide" through apoptosis mediated by the "ligand/receptor pair" FasL/Fas has been advanced as an explanation for beta-cell destruction in Type I diabetes, although conflicting experimental results have been given [24, 25]. TRAIL and its two death signalling receptors, R1 and R2, are closely related to FasL and Fas, respectively $[8,13]$, suggesting similar mechanisms of death signalling. LIGHT (another member of TNF family) transgenic mice spontaneously develop autoimmune diabetes [26]. These prompted us to investigate the expression and regulation of TRAIL and TRAIL receptors in islet cells and TRAIL-mediated cytotoxicity and apoptosis to beta cells. To investigate whether apoptosis and/or cytotoxic necrosis can be related to activation of the TRAIL death pathway in human beta cells, we examined the expression and function of this pathway in human primary islet cells and two human beta-cell lines in this study. Expression of TRAIL by activated $\mathrm{T}$ lymphocytes suggests that it could be involved in $\mathrm{T}$ cell-mediated cytotoxicity $[27,28]$. Therefore, we also examined the TRAIL expression of beta-cell antigen-specific CILs derived from new onset Type I diabetes.

\section{Materials and methods}

Human pancreatic primary islet cells and beta-cell lines. Freshly isolated human pancreatic primary islet cells from five naïve beta cell (NBC) donors (NBC 7 to 11) were provided kindly by the Islet Resource Centers of the Juvenile Diabetes Research Foundation. SV40 viral DNA-transformed human islet beta-cell line HP62 [29] and a human insulinoma-cell line CM [30] were kindly provided respectively by Dr. M. Vivis of University, Autonomous University of Barcelona, Spain and Dr. P.E. Beales of St Bartholomew's Hospital, UK. These two cell lines are good target beta cells of TRAIL, although both of them now do not release insulin in a general culture condition like most long-term cultured beta-cell lines derived from rats or mice.

Antibodies. To examine the expression of TRAIL on beta-cell lines CM and HP62, primary islet cells, and T cells, single-cell suspensions of these cells were strained with PE-conjugated mouse anti-human TRAIL monoclonal antibodies (mAbs) (clone RIK-2, BD PharMingen,, Mountain View, Calif., USA). To test TRAIL receptor expression on the cell surface, goat anti-human TRAIL-R1, rabbit anti-human TRAIL-R2, goat antihuman TRAIL-R3, and goat anti-human TRAIL-R4 polyclonal antibodies (R \& D Systems, Minneapolis, Minn., USA) were used as first antibodies in flow cytometric analyses. These antibodies were also used in cytotoxicity assays to examine their inhibition on the TRAIL pathways. MAbs (clone E2E3) (Coulter-Electronics of Canada, Burlington, Ontario, Canada) against insulin were used to test the intracellular insulin in primary beta cells.

Recombinant TRAIL, TRAIL receptors, and other recombinant cytokines. Soluble recombinant human TRAIL and other human cytokines such as FasL, TNF- $\alpha$, LT- $\alpha 1 \beta 2$, LT $\alpha 2 \beta 1$, LIGHT and IFN- $\gamma$ (R \& D Systems) were used as effector ligands to induce cytotoxicity and apoptosis in beta-cell lines and primary islet cells isolated from donors. Recombinant TRAIL-R1/Fc Chimera, TRAIL-R2/Fc Chimera, TRAIL-R3/Fc Chimera, and TRAIL-R4/Fc Chimera (R \& D Systems) were used to assess the specificity of TRAIL/TRAIL receptor interaction pathway and to test their inhibition on the TRAIL death pathway. The recombinant TRAIL receptor proteins were coded by an extracellular domain of human TRAIL receptors fused to the carboxy-terminal 6x histidine-tagged Fc region of human IgG, via a polypeptide linker. The chimeric protein was expressed in a mouse myeloma-cell line, NSO. TNFR1/Fc Chimera and Fas/Fc Chimera (R \& D Systems) were used as controls to test the specificity of TRAIL/TRAIL receptor interaction. 
RT-PCR assays. RT was carried out on total RNA isolated from CM, HP62, T cells or primary islet cells using TRIzol (GIBCO, Rockville, Mass., USA). The reaction mixture of $20 \mu \mathrm{l}$ contained $5 \mu \mathrm{g}$ RNA, $200 \mathrm{U}$ M-MLV Reverse Transcriptase (GIBCO), $250 \mu \mathrm{mmol} / \mathrm{l}$ dNTPs, 1 U Rnasin Ribonuclease Inhibitor; PCR was carried out in a $50 \mu \mathrm{l}$ reaction solution containing $10 \mathrm{mmol} / \mathrm{l}$ Tris- $\mathrm{HCl}$ (pH 8.0), $30 \mathrm{mmol} / \mathrm{l} \mathrm{KCl,} 2 \mathrm{mmol} / \mathrm{l}$ $\mathrm{MgCl}_{2}, 15 \mu \mathrm{mol} / \mathrm{l}$ each of upstream and downstream primer pairs, $200 \mu \mathrm{mol} / 1 \mathrm{dNTPs}$ and $1 \mathrm{U}$ Taq polymerase (GIBCO). Amplification for 30 cycles was done for $45 \mathrm{~s}$ each at $94^{\circ} \mathrm{C}$, $55^{\circ} \mathrm{C}$, and $72^{\circ} \mathrm{C}$. The primers pairs specific for the human TRAIL, TRAIL receptors R1, R2, R3, R4, FasL, Fas, TNF- $\alpha$, TNFR1 and TNFR2 genes ( R \& D Systems) were used to amplify these genes. The PCR products were electrophoresed on a $2 \%$ Tris acetate EDTA agarose gel and were visualized under ultraviolet light after staining with ethidium bromide and analyzed by Molecular Analyst Software (Bio Rad Laboratories, Herculies, Calif., USA). Equivalent loading was confirmed by using actin primer pair (SIGMA, St. Louis, Mo., USA) for RT-PCR assays to test actin mRNA in loading samples.

Antigenic peptides. Beta-cell antigenic peptides encompassing residues 9 to 23 and 12 to 20 of human insulin $\beta$ chain (INSB) protein were synthesized in an automated ABI 430A peptide synthesizer (Syndrgy, Foster City, Calif., USA) using standard solid-phase methods $[31,32]$. The identity and the purity of the peptides were analyzed by mass spectrometry. For each peptide, amino acid analyses were carried out and found to be in agreement with the theoretical composition.

Beta-cell peptide-specific T-cell clones. We used two T-cell clones, CD4+ THINSB1 and CD8+ THINSB2 for this study. These clones were derived from a new-onset Type I diabetic patient whose $\mathrm{T}$ cells responded well to beta-cell antigenic peptide INSB(9-23) [33, 34, 35]. Patient informed consent was obtained from the patient and patient's parents. The minimal epitopes and HLA restriction of the two T-cell clones have been identified [32, 34]. INSB(13-21) and INSB(12-20) are the minimal epitopes of cloned THINSB1 cells and THINSB2 cells respectively. The T-cell clones THINSB1 and THINSB2 were maintained in culture by stimulating $2 \times 10^{5}$ cell at weekly intervals with the specific peptides INSB(9-23) and INSB(12-20) respectively at $10 \mu \mathrm{mol} / 1$ in complete RPMI 1640 medium containing 5\% Lymphocult-T-LF (Biotest, Dreieich, Germany), $50 \mathrm{U} / \mathrm{ml}$ human recombinant interneukin-2 (rIL-2) (GIBCO, Missisauga, Ontario, Canada), and $\gamma$-irradiated (3000 rad) autologous peripheral blood mononuclear cells (PBMC) $\left(2 \times 10^{6} / \mathrm{ml}\right)[33,34]$. Phytohemagglutinin (PHA, SIGMA) and anti-CD3 mAb (BD PharMingen) were used to activate T cells from the same donor of T-cell clones for controls.

Cytotoxicity assay. Standard ${ }^{51} \mathrm{Cr}$ release assays [34, 35] were used to measure cytotoxicity activity of cytokines. For use as target cells in cytotoxicity assays, apoptosis assays and flow cytometric analyses, freshly isolated (primary or naïve) islet beta cells were harvested from culture and digested into singlecell suspension by PBS with liberase HI (Roche Diagnostics, Indianapolis, Ind., USA) at $0.75 \mathrm{mg} / \mathrm{ml}$, trypsin $0.8 \mathrm{mg} / \mathrm{ml}$ (Gibco BRL), and $0.25 \%$ EDTA for $5 \mathrm{~min}$ at $37^{\circ} \mathrm{C}$. The primary islet-cell preparation contained over $90 \%$ dithizone (DTZ) stained-islet cells of which over $75 \%$ are beta cells expressing intracellular insulin identified by anti-insulin antibody of clone E2E3. $1 \times 10^{6}$ of CM, HP62, or primary islet cells were internally labelled for $1 \mathrm{~h}$ at $37^{\circ} \mathrm{C}$ with $7.4 \mathrm{MBq} / \mathrm{ml}$ of $\mathrm{Na}_{2}{ }^{51} \mathrm{CrO}_{4}$ (Amersham, Oakville, Ontario, Canada). Radiolabelled target cells were washed four times with medium, then, incubated for
$4 \mathrm{~h}$ at $37^{\circ} \mathrm{C}$ with cytokines at different concentrations in roundbottom 96-well plates (Nunc, Napierville, Ill., USA). All assays were carried out in triplicate. Percent cytotoxicity was calculated by the formula: $100 \times[($ ER-SR $) /(M R-S R)]$, where $\mathrm{ER}\left(\right.$ experimental ${ }^{51} \mathrm{Cr}$ release $)=$ mean $\mathrm{cpm}$ released into the supernatant in the presence of cytokines, using $5 \times 10^{3}$ target cells/well; SR (spontaneous ${ }^{51} \mathrm{Cr}$ release) = mean $\mathrm{cpm}$ in the absence of cytokines assessed in four replicate samples, and MR (maximal ${ }^{51} \mathrm{Cr}$ release) $=$ mean $\mathrm{cpm}$ in supernatant of target cells incubated with $0.5 \%$ Nonidet-P40 (NP-40) detergent (SIGMA) assessed in four replicates. SR was always less than $20 \%$ of MR.

To test the influence of reagents such as cycloheximide (CHX) and phosphatidylinositol-specific phospholipase $\mathrm{C}$ (PI-PLC) (SIGMA) on the susceptibility of human primary islets cells to the TRAIL death pathway, we incubated islet cells that were resistant to TRAIL-mediated cytotoxicity with $\mathrm{CHX}$ at a concentration of $10 \mu \mathrm{g} / \mathrm{ml}$ for $48 \mathrm{~h}$ or with PI-PLC at a concentration of $1 \mu \mathrm{g} / \mathrm{ml}$ for $2 \mathrm{~h}$ before the islet cells were labelled with $\mathrm{Cr}^{51}$ and exposed to TRAIL in cytotoxicity assays.

Flow cytometric analysis. To examine the expression of TRAIL on primary islet beta cells, CM, HP62 and T cells, single-cell suspensions of these cells were strained with PE-conjugated mouse anti-human TRAIL (clone RIK-2). To test the TRAIL receptor expression on the cell surface, goat anti-human TRAIL-R1, R3, or R4 polyclonal antibodies, and rabbit anti-human TRAIL R2 polyclonal antibodies ( R \& D Systems) were used as first antibodies to label these cells respectively with purified goat $\mathrm{IgG}$ or rabbit $\mathrm{IgG}$ as controls (SIGMA). Biotin-conjugated mouse anti-goat IgG or antirabbit IgG (Chemicon International, Temecula, Calif., USA) were then used as second antibodies to label these cells before staining with FITC-conjugated streptavidin (Chemicon) for flow cytometric analyses. The Annexin V assay was used to detect the abnormal proteins in plasma of the cells at an early stage of apoptosis. FITC-conjugated Annexin V (BD PharMingen) was used to stain the translocated membrane phospholipid phosphatidylserine on the surface of cells before these cells were analyzed by flow cytometry. 7-amino-actinomycin (7-AAD) (BD PharMingen) was used to assess plasma membrane integrity in Annexin V apoptosis assays. 7-AAD is a fluorescent vital dye that stains DNA in cells. It does not cross the plasma membrane of the cells that are viable or in the early stages of apoptosis, because plasma membrane integrity is still retained. In contrast, cells in the late stages of apoptosis or cells that are already dead have lost plasma membrane integrity and are permeable to 7-AAD. An APO-DIRECT assay which utilizes a reaction catalyzed by exogenous TdT, referred to as "end-labelling" or "TUNEL" assay, was also used to detect fragmented DNA of the apoptotic cells in this study. Fluorescein deoxyuridine triphosphate (FITC-dUTP) and propidium iodide (PI) (BD PharMingen) were used to stain the DNA breaks and total DNA of the apoptotic cells following flow cytometric analysis. Data were collected using a FACS Calibur (BD Pharmingen) and analyzed with CellQuest (BD Biosciences).

Statistical analysis. All positive results were verified by carrying a two-tailed Student's $t$ test of the mean apoptosis (or cytotoxicity) obtained with cytokine (or chemical)-treated and -untreated (negative control) beta (or primary islet) cells. Significance of the mean apoptosis (or cytotoxicity) in a group of beta (or primary islet) cells treated by individual cytokine, compared with those treated by other cytokines at the same conditions (concentration and time) was examined by post hoc test using analysis of variance (ANOVA). 
A

$$
\begin{aligned}
& \frac{\mathrm{CM}}{\mathrm{M}-+++\cdot \mathrm{M}+++++\mathrm{M}+++++} \frac{\mathrm{HP} 2}{\mathrm{NBC}}
\end{aligned}
$$

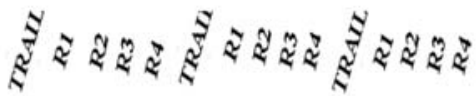

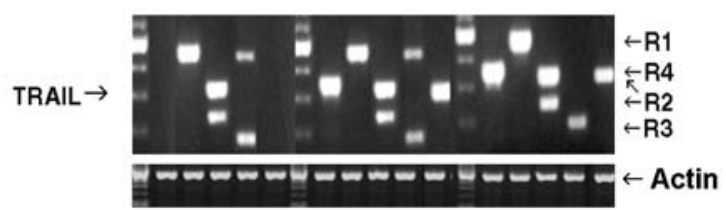

Fig. 1A, B. Expression of TRAIL receptors R1, R2, R3, R4 and /or TRAIL in human primary islet cells and beta cell lines. A RT-PCR assays show the presence of mRNA of TRAIL and TRAIL receptors expressed in primary islet cells and two betacell lines CM and HP62. Equivalent loading was confirmed by using actin mRNA. (Primary islet cells from all fiver donors showed similar levels of expression. The representative results
B

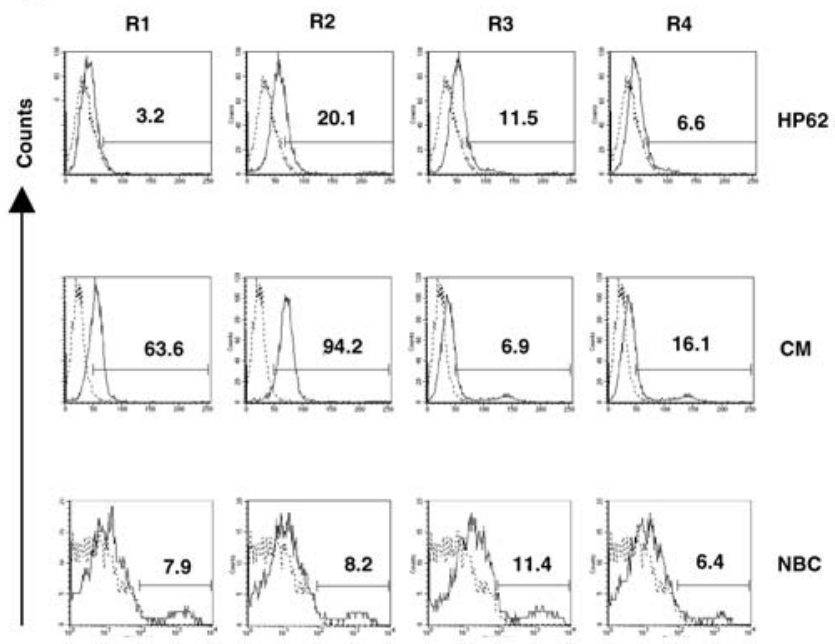

of islet cells from one donor are shown here). B Flow cytometric analyses indicated that HP62, CM, and normal primary islet cells express TRAIL receptors on their cell surface. The solid line histograms denote the staining by anti-TRAIL receptor antibodies. The dotted line histograms denote the staining by unrelated control antibodies with the same isotypes. The percentages of positive cells are also shown
A.

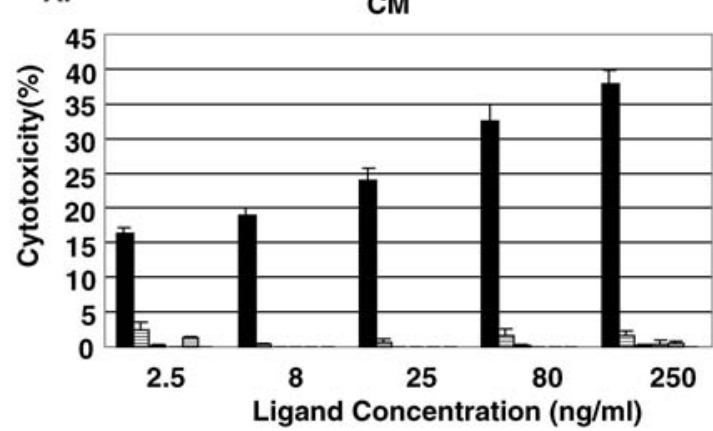

B.

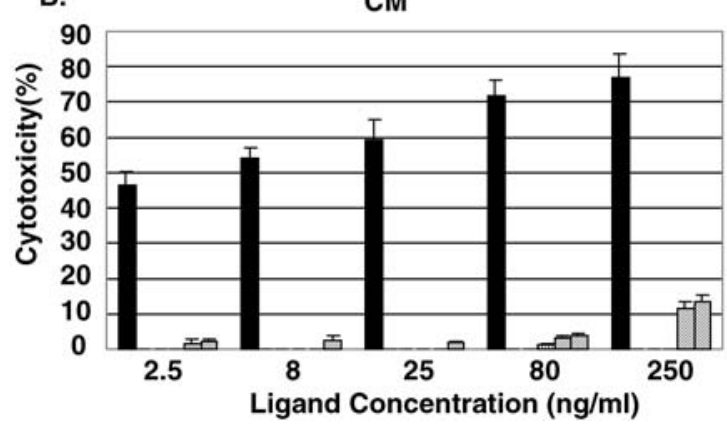

Fig. 2A, B. Cytotoxicity to CM and HP62 beta cells mediated by soluble cytokines TRAIL, FasL, TNF- $\alpha$, LT $\alpha 1 \beta 2$, LT $\alpha 2 \beta 1$, LIGHT, and IFN- $\gamma$. A Results from 4-h cytotoxicity assays are shown. B Results from 18-h cytotoxicity assays are shown

\section{Results}

Human beta-cell line HP62, insulinoma-cell line CM, and freshly isolated primary islet cells express TRAIL receptors $R 1, R 2, R 3, R 4$ and/or TRAIL. To examine

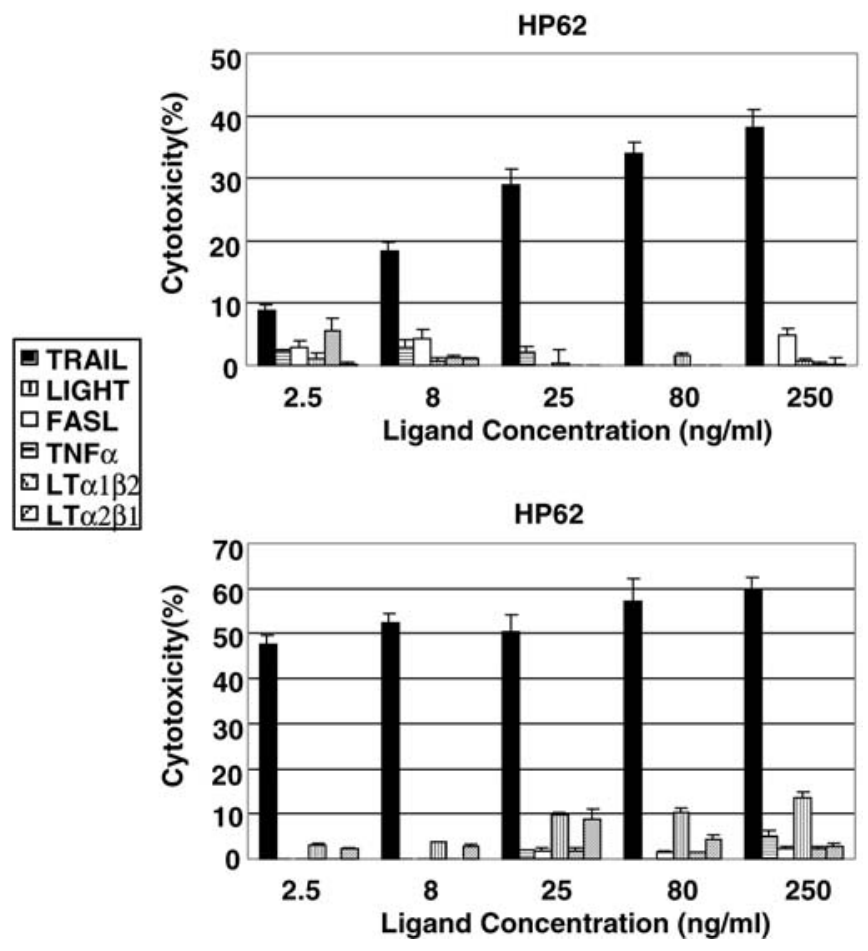

whether the specific components of the TRAIL death pathway are present in human beta cells, we investigated the mRNA expression of TRAIL receptors R1, $\mathrm{R} 2, \mathrm{R} 3$ and R4 in primary islet cells freshly isolated from human donors and in beta-cell lines, CM and HP62 using RT-PCR assays. Primary normal islet cells from five NBC donors all showed positive mRNA of TRAIL-R1, -R2, -R3, and -R4 as well as TRAIL in RT-PCR assays (Fig. 1A). Beta-cell line HP62 also expressed mRNAs of the four TRAIL receptors as well 
as TRAIL mRNA. However, insulinoma CM cells expressed mRNAs of R1, R2, and R3 but not mRNAs of R4 and TRAIL in the RT-PCR assays. The beta-cell lines and primary islet cells were also examined for the expression of TRAIL and TRAIL-receptor proteins on their cell surface by flow cytometric analyses(Fig. 1B). Consistent with the results in RT-PCR assays, the results showed that all of these cells express TRAIL receptors, although the extent of expression was variable among the cells tested. Why CM cells expressed R4 in flow cytometric assays but not in RT-PCR assays remains unclear (repeated experiments showed the same results). It is possible that the gene coding R4 in $\mathrm{CM}$ cells is different from other beta cells at the site binding to the primers used in this study but is the same as them at protein $\mathrm{R} 4$ site recognized by anti-R4 antibodies used in this study. CM and HP62 cells expressed higher densities of R2 than primary islet cells. CM cells showed relatively higher densities of R1 and R2 than did HP62 and primary islet cells (Fig. 1B).

TRAIL induced much stronger cytotoxicity and apoptosis in human beta-cell lines CM and HP62 than did FasL, TNF- $\alpha, L T \alpha 1 \beta 2, L T \alpha 2 \beta 1, L I G H T$, and $I F N-\gamma$. To investigate whether the TRAIL death pathway is functional in mediating beta-cell destruction, we used soluble recombinant TRAIL to test its effect on the beta-cell lines CM and HP62 cells and on primary islet cells. For comparison, soluble TRAIL as well as other cytokines that are potential ligands inducing target-cell damage, such as FasL, TNF- $\alpha$, LT $\alpha 1 \beta 2$, LT $\alpha 2 \beta 1$, LIGHT, and IFN- $\gamma$, was used as effectors to induce beta-cell destruction in apoptosis assays and cytotoxicity assays. TRAIL showed clear cytotoxicity to insulinoma-cell line CM and beta-cell line HP62, even at very low concentrations $(2.5 \mathrm{ng} / \mathrm{ml}, p<0.01)$ in standard $(4-\mathrm{h}){ }^{51} \mathrm{Cr}$ release assays. The cytotoxicity of TRAIL to these cells was dose-dependent (Fig. 2). TNF- $\alpha, \quad$ LT $\alpha 1 \beta 2$ and LT $\alpha 2 \beta 1$ were cytotoxic to these beta cells only in long-term (18-h) cytotoxicity assays and at higher concentrations (Fig. 2B), although the mRNAs of the receptor TNF-R1 were positive in these cell lines shown in RT-PCR assays. FasL and LIGHT showed no cytotoxicity to CM and HP62 beta cells even in long-term cytotoxicity assays and at high concentration $(250 \mathrm{ng} / \mathrm{ml})$, although these cells showed positive Fas mRNA (Fig. 2). The cytotoxicity of TRAIL to these beta cells was obviously inhibited by soluble TRAIL receptors R1, R2, R3 and R4 at a 5:1 molar ratio of TRAIL receptor/TRAIL (Fig. 3A). R1 and R2 showed stronger ability than R3 and R4 in inhibition of the beta-cells damage induced by TRAIL at lower TRAIL receptor/TRAIL ratios. TRAIL-R1 and -R2 were able to completely inhibit the cytotoxic effects of TRAIL at a receptor/ TRAIL ratio $=1.5$ at molar concentrations $(p<0.0001$, Fig. 3B, C), while R3 and R4 showed strong blockade only at over 5:1 molar con-
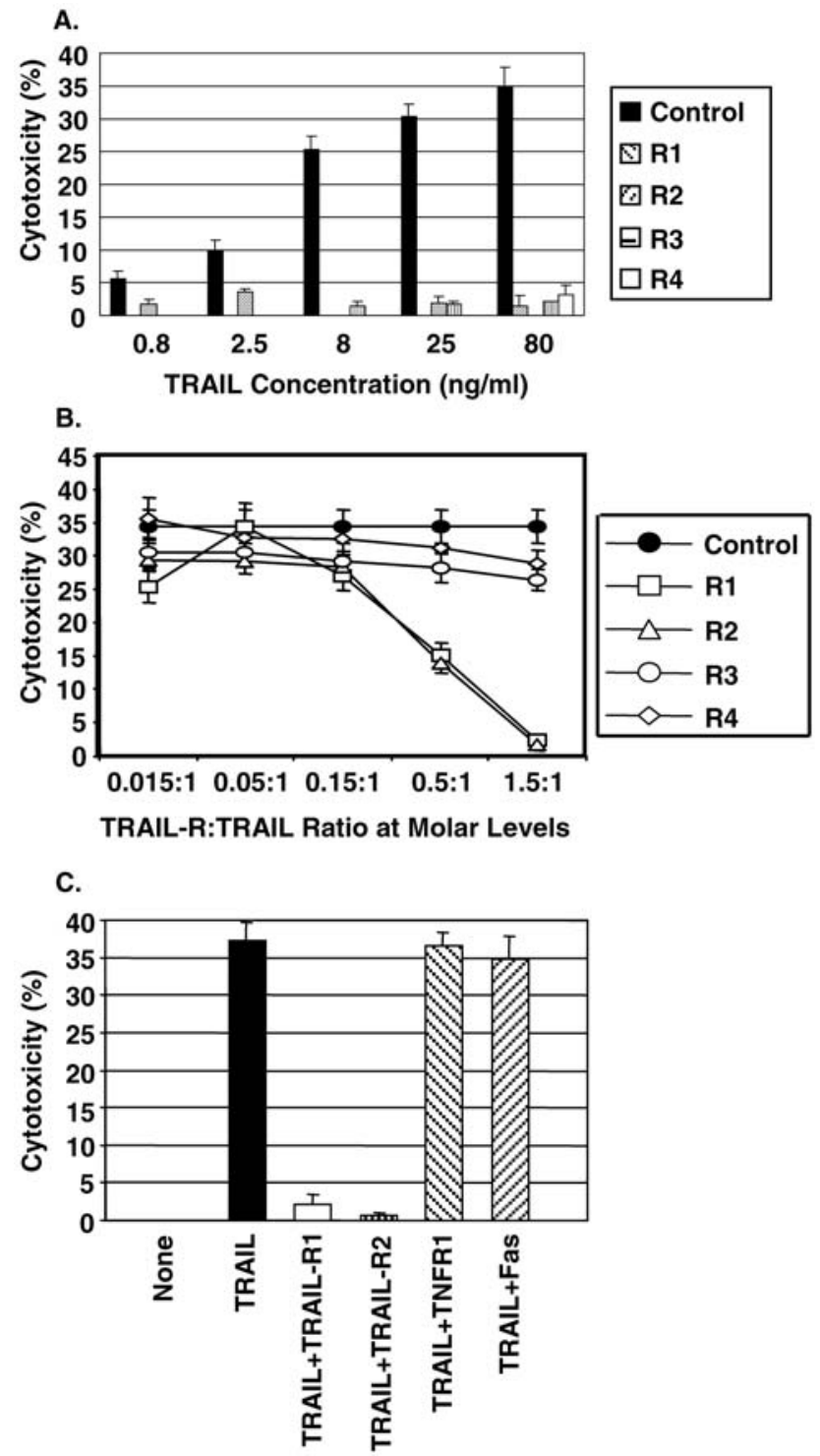

Fig. 3A-C. Competitive inhibition of the cytotoxicity of TRAIL to CM cells by soluble TRAIL receptors. A TRAIL receptor/TRAIL ratio $=5: 1$ at molar levels. $\mathbf{B}$ TRAIL receptor/TRAIL at different ratios as shown. TRAIL concentration used is $80 \mathrm{ng} / \mathrm{ml}$. C TRAIL concentration used is $80 \mathrm{ng} / \mathrm{ml}$. TRAILreceptor/TRAIL ratio $=5: 1$ at molar levels

centrations (Fig. 3A). Other cytotoxic ligand receptors such as TNFR1 (the receptor of TNF- $\alpha$ ) and Fas (the receptor of FasL) were not able to inhibit TRAILmediated cytotoxicity to CM cells, suggesting the specificity of interaction of TRAIL and TRAIL receptors (Fig. 3C). Treatment of CM cells with antibodies against human TRAIL receptors could block the cytotoxicity of TRAIL to these cells to different extents. Antibodies against R2 $(p<0.0001)$ were able to completely block the cytotoxicity of TRAIL to CM cells, however, R1 $(p<0.001)$ and R4 $(p<0.01)$ antibodies could inhibit only $70 \%$ and $20 \%$ of cytotoxicity, respectively, and the R3 $(p<0.065-0.095)$ antibodies were not able to protect these cells from the cytotoxic- 
ity of TRAIL at concentration of $80 \mathrm{ng} / \mathrm{ml}$ (Fig. 4). R4 antibodies also block some of the cytotoxicity of TRAIL to CM cells, although R4 is usually considered a decoy receptor. Different from R4 which contains a truncated cytoplasmic death domain, R3 has no an intracellular domain. This could explain why R3 antibodies show no clear influence on the cytotoxicity of TRAIL to CM cells. These results indicate that the cytotoxicity of TRAIL to the insulinoma CM cells was mediated by the interaction between TRAIL and TRAIL receptors and that TRAIL death pathway might be mainly mediated via TRAIL-R1 and -R2, partly mediated through -R4 but not -R3. Two differ-

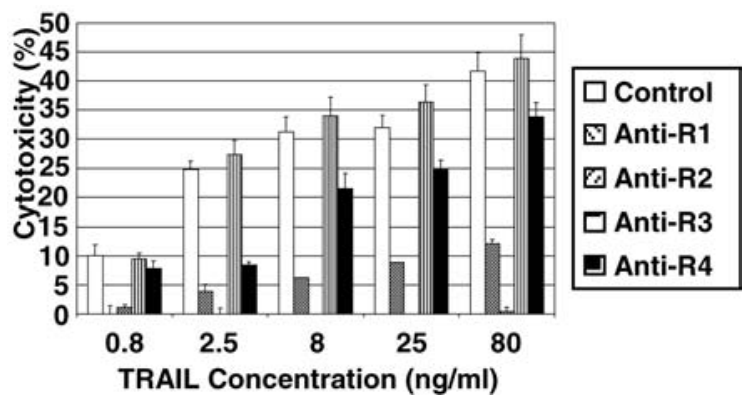

Fig. 4. Blockade of the cytotoxicity of TRAIL to CM cells by antibodies against TRAIL receptors. CM cells were incubated with antibodies at TRAIL/anti-TRAIL-R ratio $=1: 10$ at molar levels for $1 \mathrm{~h}$ before exposure to TRAIL in cytotoxicity assays

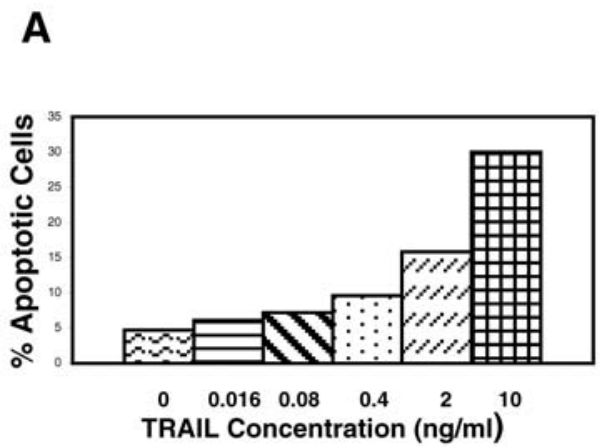

B

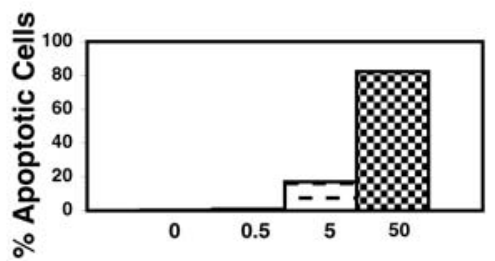

TRAIL Concentration (ng/ml)

Fig. 5A, B. Ligand dose-dependent apoptosis of CM cells induced by TRAIL. A The apoptosis of CM cells induced by TRAIL in AnnexinV assays. The influence of dose on apoptosis of CM cells induced by TRAIL $(24 \mathrm{~h})$ is shown. A representative result (density plot) of the apoptosis of CM cells induced by TRAIL at $10 \mathrm{ng} / \mathrm{ml}$ for $24 \mathrm{~h}$ is also shown here. B Dose-dependent responses of apoptosis of CM cells ent flow cytometric assays, the Annexin V assay and the TUNEL assay, were used to test TRAIL-induced beta-cell apoptosis. To analyse the kinetic relation between TRAIL action time and apoptosis induced by TRAIL to CM cells, our preliminary experiments showed that Annexin V-positive (7-AAD-negative) cells appeared first and their percentage increased with increased time of incubation with TRAIL, to a maximun at 4 hour, and then decreased. However, the percentage of cells staining positive with both Annexin $\mathrm{V}$ and 7-ADD increased more slowly and exceeded the percentage of cells with only Annexin V-positive staining after $8 \mathrm{~h}$ of incubation with TRAIL. TRAILinduced CM-cell apoptosis was TRAIL dose-dependent in both the Annexin V assay and TUNEL assay (Fig. 5). TRAIL could induce clear CM-cell apoptosis after incubation with these cells for $4 \mathrm{~h}$ at a concentration of $10 \mathrm{ng} / \mathrm{ml}(p<0.0001$, Fig. 6A). However, FasL $(p<0.026)$, TNF- $\alpha(p<0.020)$, LT $\alpha 2 \beta 1(p<0.026)$, and IFN- $\gamma(p<0.021)$ induced much lower CM-cell apoptosis than did TRAIL at a concentration of $10 \mathrm{ng} / \mathrm{ml}$ for $4 \mathrm{~h}$ (Fig. 6A) and $24 \mathrm{~h}$. LT $\alpha 1 \beta 2(p<0.064)$ and LIGHT $(p<0.068)$ did not induce apoptosis of CM cells at the same conditions (Fig. 6 A). The other cytokines also induced apoptosis of CM and PH62 cells to a lesser extent than did TRAIL, when these cells were incubated with them at as high a concentration as $200 \mathrm{ng} / \mathrm{ml}$ for $24 \mathrm{~h}$ (Fig. 6B).

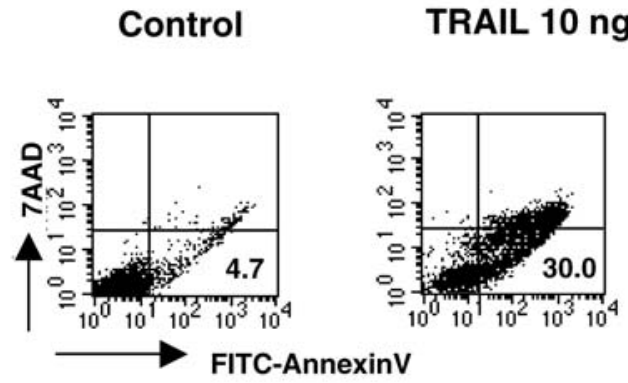

TRAIL $50 \mathrm{ng}$

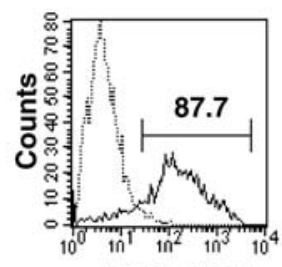

FITC-dUTP

induced by TRAIL $(24 \mathrm{~h})$ in TUNEL assays are shown. A representative result (histograms) of the apoptosis of CM cells induced by TRAIL at a concentration of $50 \mathrm{ng} / \mathrm{ml}(24 \mathrm{~h})$ is also shown. The solid line histograms denote the TRAILtreated CM cells. The dotted line histograms denote the untreated control CM cells. The percentages of positive cells are shown 
A

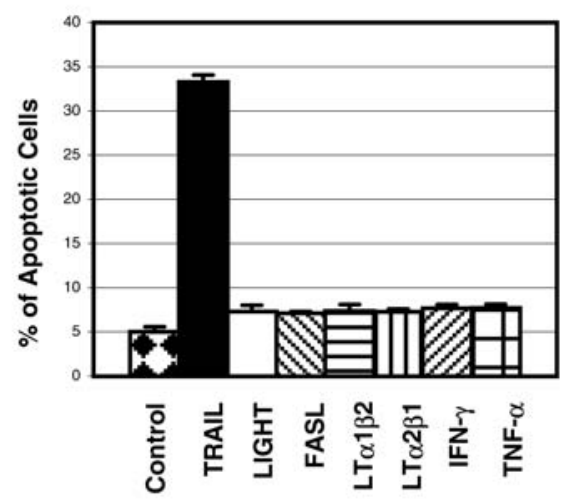

B

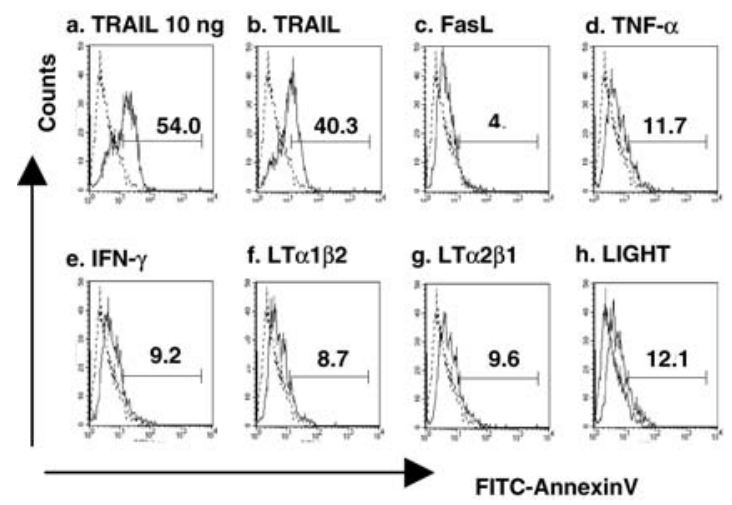

Fig. 6A, B. Comparison of CM-cell apoptosis induced by TRAIL and other cytokines FasL, TNF- $\alpha$, LT $\alpha 1 \beta 2$, LT $\alpha 2 \beta 1$, LIGHT, and IFN- $\gamma$. A The apoptosis of CM cells was induced by TRAIL or other cytokines at a concentration of $10 \mathrm{ng} / \mathrm{ml}$ in 4-h Annexin V assays. The results from three repeated experiments are shown here. B (a) Apoptosis of CM cells was induced by TRAIL at a concentration of $10 \mathrm{ng} / \mathrm{ml}$ in a $24-\mathrm{h}$ apoptosis assay (other cytokines did not induce clear apoptosis of CM cells at these conditions. Those results are omitted). (b-h) The apoptosis of CM cells induced by TRAIL and other cytokines as shown was tested at a concentration of $200 \mathrm{ng} / \mathrm{ml}$ in 24-h Annexin V assays. The solid line histograms denote the cytokine-treated CM cells. The dotted line histograms denote the untreated CM cell controls. The percentages of positive cells are also shown

Beta-cell antigen-specific CTL clones express TRAIL. PE-labelled monoclonal antibodies (clone RIK-2) against human TRAIL were used to stain beta-cell antigen (INSB)-specific CTL clones CD4+ THINSB1 and $\mathrm{CD}^{+}$THINSB2 for flow cytometric analyses. $45.9 \%$ of INSB (13-21)-specific CD4+ THINSB1 clone cells are TRAIL-positive. Of cloned CD8 ${ }^{+}$ THINSB T cells specific to INSB(12-20) $58.8 \%$ expressed TRAIL on the cell surface (Fig. 7A). RT-PCR assays also showed that these beta-cell antigenactivated T cells are TRAIL mRNA-positive and are TRAIL receptor mRNA(s)-positive (Fig. 7B). Similar results were shown in T-cell clones specific to other beta-cell proteins such as GAD and IA-2. The PBMC from the same donors were almost all TRAIL-
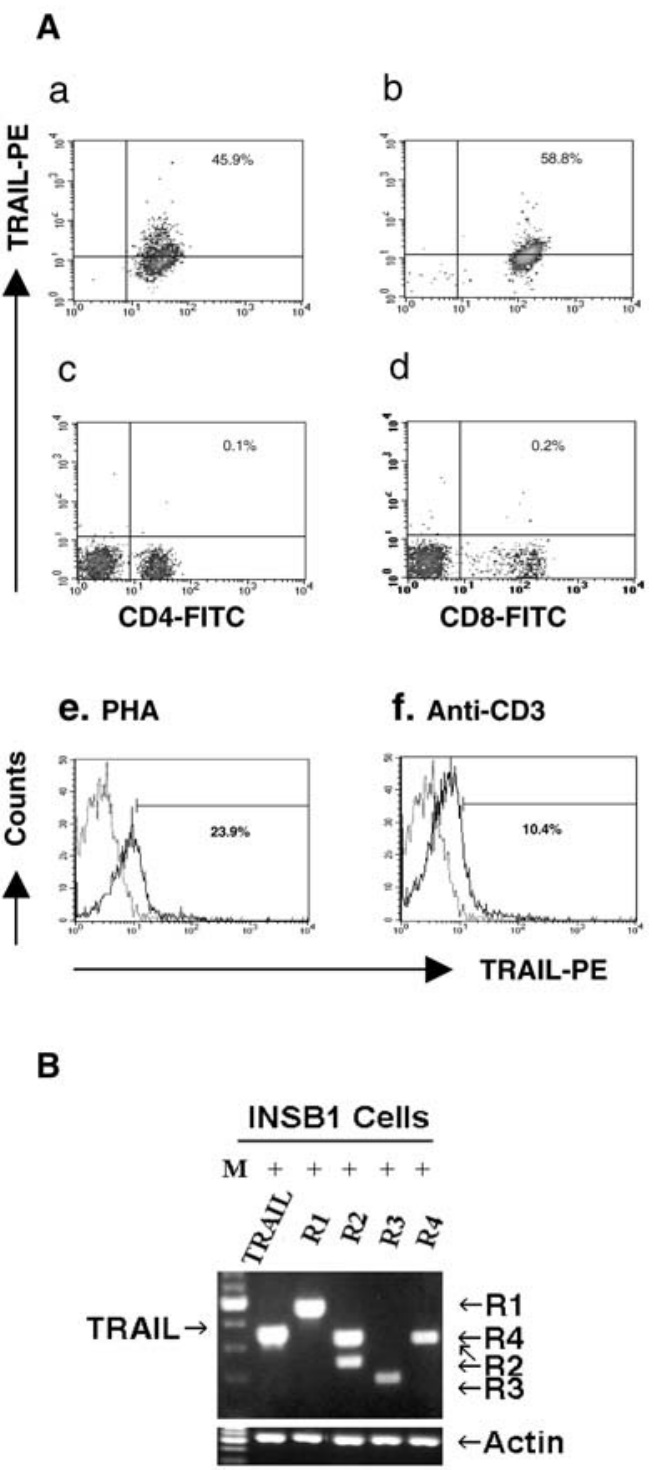

Fig. 7A, B. TRAIL expression of beta-cell antigen-specific CTL clones. A a and b show TRAIL expression on the cell surface of CD4+ THINSB1 (a) or CD8+ THINSB2 (b) CTL clones specific to peptides of INSB in flow cytometric analyses. (c) and (d) show TRAIL expression on PBMC cells surface from the same donor of the T-cell clones. e and $f$ show TRAIL expression on PHA-activated (at $10 \mu \mathrm{g} / \mathrm{ml}$ ) (e) and anti-CD3 mAb-activated (at $300 \mathrm{ng} / \mathrm{ml}$ ) (f) PBMC from the donor. B RT-PCR assays show mRNA expression of TRAIL and TRAIL receptors in cells of T-cell clone THINSB1. Equivalent loading was confirmed by using actin mRNA

negative on their cell surface (Fig. 7A) . However, activated $\mathrm{T}$ cells derived from PBMC of these donors by stimulation with PHA or anti-CD3 mAb also showed positive TRAIL on the cell surface (Fig. 7A).

Multiple factors influenced the susceptibility of normal islet cells to the damage mediated by the TRAIL death pathway. We tested TRAIL-mediated cytotoxicity to freshly isolated primary human beta cells from five donors. TRAIL showed clear cytotoxicity to primary beta 


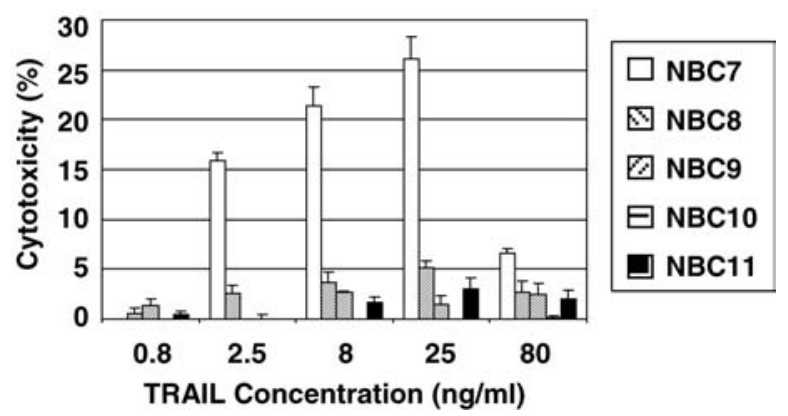

Fig. 8. Cytotoxicity of TRAIL to freshly isolated primary islet cells from five donors (4-h assays)

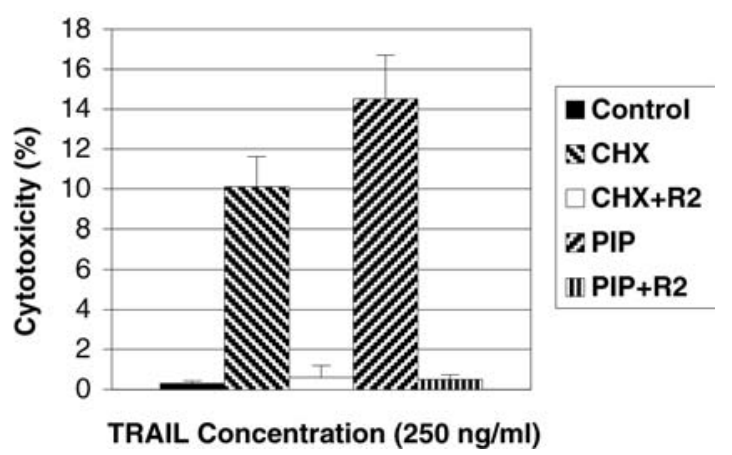

Fig. 9. Effect of addition of CHX or PI-PLC on the susceptibility of primary islet cells to TRAIL-mediated cytotoxicity. TRAIL-resistant primary islet cells from donor NBC11 were treated with CHX at $10 \mu \mathrm{g} / \mathrm{ml}$ for $48 \mathrm{~h}$ or treated with PI-PLC (PIP as shown in legend) at $1 \mu \mathrm{g} / \mathrm{ml}$ for $2 \mathrm{~h}$ before use as target cells in cytotoxicity assays. Untreated primary islet cells as well as CHX- (or PI-PLC)-treated islet cells plus TRAIL-R2 at concentration of TRAIL-R2/TRAIL ratio $=5$ (at molar level) were used as controls in 4-h cytotoxicity assays

cells from only one donor at different concentrations from $2.5 \mu \mathrm{g} / \mathrm{ml}$ to $80 \mu \mathrm{g} / \mathrm{ml}$, with marginal or negative cytotoxicity to primary islet cells from the other four donors, suggesting that most normal islet cells were resistant to TRAIL-induced cytotoxicity (Fig. 8). To study the factors influencing the susceptibility of normal primary islet cells to the TRAIL death pathway, we treated primary islet cells with CHX and PI-PLC before exposing these cells to TRAIL. Normal primary islet cells from donor NBC11 that were resistant to TRAIL-mediated cytotoxicity (Fig. 8) became susceptible to the cytotoxicity mediated by TRAIL after these cells were treated by CHX $(\mathrm{P}<0.0001)$ and PI-PLC $(\mathrm{P}<0.0001)$ (Fig. 9). However, the presence of TRAIL receptor R2 blocked the cytotoxicity of TRAIL to the treated islet cells suggesting that treatment of primary islet cells with CHX or PI-PLC increased the susceptibility of these cells to TRAIL-induced damage.

\section{Discussion}

We have shown in this study that TRAIL-R1, -R2, -R3 and/or -R4 mRNA is expressed in normal primary islet cells and in beta-cell lines CM and HP62. These cells also expressed TRAIL receptors on their cell surface. This is the first instance in which TRAIL has been shown to kill normal human primary islet cells and beta-cell lines. This study proves that the TRAIL death pathway is functional in human beta cells and is likely to be mediated through TRAIL-R1 and -R2.

There are multiple potential pathways (such as perforin, FasL and TNF- $\alpha$ ) mediating apoptosis and/or cytotoxicity to beta cells. Recently, FasL/Fas interaction has received attention as an explanation for autoimmune beta-cell destruction in Type I diabetes [24, 25]. However, little is known about which are the most important pathways mediating beta-cell damage in Type I diabetes. This does not preclude the possibility that TRAIL could be acting through its death receptors in a manner postulated for FasL in Type I diabetes. The results in this study showed that TRAIL induced much stronger cytotoxicity and apoptosis to human beta-cell lines CM and HP62 than did other cytokines suggesting the potential roles of TRAIL pathways in the development of Type I diabetes. The TRAIL death pathway showed two important characterisations, in comparison with pathways mediated by other TNF family members. Firstly, as a death-pathway ligand, TRAIL has the most complex receptor system including two true receptors (R1 and R2), two decoy receptors (R3 and R4) and a fifth receptor, osteoprotegerin, compared with TNF- $\alpha$ (a true receptor TNFR1 and a decoy receptor TNFR2) and FasL (a true receptor Fas and a decoy receptor, DcR3) [36]. Secondly, the signal-transduction pathway initiated by TRAIL is complex and could be different from those triggered by other death ligands. Death ligands FasL, TNF- $\alpha$ and TWEAK via receptors Fas, TNFR1 and DR3, respectively initiate apoptosis through recruitment of a common adaptor protein FADD or TRADD/FADD. FADD in turn recruits caspase 8 to form the death-inducing signalling complex, which leads to activation of a caspase cascade and eventual cell death. While the activating events start different signal cascades, all of these communications feed into a final, common apoptotic pathway that leads to cell death $[36,37]$. However, the role of FADD in TRAIL receptors is highly controversial. Several initial papers showed that the TRAIL-induced death pathway was FADD-independent, and that the dominant negative FADD protein failed to inhibit apoptosis initiated by overexpression $[36,38]$. A recent study showed that FADD is required for TRAIL-R1- and -R2-mediated apoptosis [39]. Therefore, the TRAIL death pathway might use both the common signal-transduction pathway (FADD-dependent pathway) shared with other ligands and a FADD-independent signal-transduction pathway, in which TRAIL directly activates caspase-3 [36]. These characteristics (multiple functional receptors and multiple signal-transduction pathways) of the TRAIL pathway might be used to explain why TRAIL 
induced stronger cytotoxicity and apoptosis to insulinoma CM cells and SV40-transformed HP62 beta cells, in comparison with the pathways initiated by FasL, TNF- $\alpha$, LT $\alpha 1 \beta 2$, LT $\alpha 2 \beta 1$, and LIGHT.

TRAIL can induce apoptosis in a wide range of transformed cell lines but not in many normal cells, although the mRNAs of TRAIL-R1 and R2 were found to be widely expressed on normal tissue [40]. Similarly, most of the normal islet cells in this study are resistant to the TRAIL death pathway, although these cells express TRAIL receptors R1 and R2. Many factors might influence the susceptibility and resistance of normal islet cells to the TRAIL pathway [40]. The normal tissue cells are believed to be protected from apoptosis by the two additional decoy receptors, TRAIL-R3 and -R4. TRAIL-R3 is an extracellular glycosyl-phosphatidylinositol-linked protein without an intracellular domain [11, 19, 41, 42]. TRAIL-R4 contains a truncated cytoplasmic death domain [20, $43,44]$. TRAIL-R3 and -R4 were thus considered to inhibit TRAIL induced apoptosis either by acting as decoy receptors or by providing inhibitory signals such as activation of the transcription factor NF- $\kappa B$ $[44,45]$ which is known to regulate several inhibitors of apoptosis (c-IAP1, c-IAP2 and XIAP) [46, 47]. In addition, the death receptors TRAIL-R1 and -R2 are also known to be able to activate NF- $\kappa \mathrm{B}$ upon ligation $[12,13,14,48,49]$. A fifth TRAIL-R, osteoprotegerin, exists predominantly in a secreted form and seems to inhibit TRAIL-induced apoptosis by competitive inhibition of TRAIL binding to the death receptors TRAIL-R1 and -R2. [50]. That CM and HP62 cells expressed higher levels of TRAIL-R2 might explain why anti-R2 antibodies showed the strongest inhibition of TRAIL-induced cytotoxicity to CM cells among 4 TRAIL receptor antibodies. This study showed the competitive inhibition by decoy receptors R3 and R4 of the TRAIL-induced effects on beta-cell lines. The antagonist decoy receptors expressed on all normal primary islet cells explain their resistant phenotype to the TRAIL pathway, similar to the primary cells of other normal tissues [13, 17]. Some studies suggested that TRAIL expression might protect target cells from the damage initiated by TRAIL, similar to FasL the expression of which in target cells protects against FasL-mediated apoptosis [51]. If this is true, then negative TRAIL expression in CM cells in RT-PCR assays might explain their susceptibility to the TRAIL death pathway. Normal islet cells show susceptibility to the TRAIL death pathway after treatment by PI-PLC, consistent with a similar study using human normal umbilical vein endothelial cells as TRAIL target cells [40]. Treatment with PI-PLC could remove the TRAIL-R3 receptors from the cell membrane $[11,40]$. As well, an inhibitor such as CHX suppressing protein synthesis might also influence the resistance of islet cells to the TRAIL death pathway [52]. Primary islet cells were found to be sus- ceptible to apoptosis mediated by TRAIL, in the presence of the protein synthesis inhibitor CHX in this study. To study the possible mechanisms of $\mathrm{CHX}$ and PI-PLC treatment on susceptibility of NBC to the TRAIL pathway, we examined the expression of TRAIL receptors on these cells before and after treatment with CHX or PL-PLC. We found that TRAIL-R3 expression was reduced by over $80 \%$ after treatment by PI-PLC [Ou] similar to other studies $[11,40]$. Both CM and HP62 cells showed higher expressions of TRAIL-R2 than primary islet cells. This might also explain the susceptibility of these beta-cell lines to cytotoxicity of TRAIL.

Beta-cell antigen-specific cytotoxic $\mathrm{T}$ cells could mediate beta-cell destruction and play an important role in the pathogenesis of Type I diabetes [32, 34, 53]. To assess whether CTL cells are the sources of TRAIL, we examined TRAIL expression on cloned beta-cell antigen (GAD, INS, or IA-2)-specific CTL $\left(\mathrm{CD}^{+}\right.$and $\left.\mathrm{CD}^{+}\right)$cells. Results showed that all the beta-cell antigen-specific CTL clones express TRAIL on the cell surface, although PBMC from the same donors of CTL clones did not express TRAIL. Our recent studies indicated that antibodies against TRAIL receptors block the non-HLA-restricted cytotoxicity of the CTL cells to CM cells $[\mathrm{Ou}]$. We also studied the TRAIL expression in islets on pancreatic paraffin wax-sections from patients with Type I diabetes in comparison with those from age-matched normal control subjects. Clear enhancement of TRAIL expression was observed in infiltrating cells of islets from acute onset Type I diabetic patients. These results suggest that the TRAIL death pathway could be a potential mechanism of beta-cell destruction mediated by CTLs and/or other immune cells in Type I diabetes. Consistent with our results, other studies showed that human autoreactive and foreign antigen-specific $\mathrm{T}$ cells expressed TRAIL [51], that PHA- (or anti-CD3)-activated T cells were able to release soluble TRAIL [54], and that TRAIL pathway was involved in $\mathrm{CD}^{+}$CTL cell-mediated cytotoxicity to target cells [55].

To date the actual biological function of TRAIL and its five receptors in vivo is still not clear. CM and HP62 cells used in this study are transformed cells that are susceptible to the TRAIL death pathway. TRAIL-induced cytotoxicity and apoptosis are important mechanisms of viral infection-mediated cell damage and CTL cell-mediated tumor-cell destruction [56, 57]. In the cases of viral infection and cancer transformation, most of the transformed cells could be susceptible to the damage mediated by TRAIL. However, not all transformed tumor cells are susceptible to the TRAIL death pathway $[40,58]$. The major factors that determine the susceptibility remain unclear $[37,52]$. There might be some unidentified changes not related to transformation leading to the susceptibility to TRAIL-mediated apoptosis in the primary beta cells. 
Therefore, further detailed study of the regulation and control of the TRAIL death pathway might lead to discoveries of benefit to the clinician in the treatment and prevention of beta-cell destruction in Type I diabetes.

Acknowledgements. We thank Dr. B.J. Hering of the JDF Islet Resource Centre of the University of Minnesota, Dr. T. Mohanakumar of the JDF Islet Resource Centre of Washington University, Dr. C. Ricordi of the Diabetes Research Institute of the University of Miami and Dr. P. Robertson of Pacific Northwest Research Institute, Dr. M. Vives of University Hospital, Autonomous University of Barcelona, Barcelona, Spain and Dr. P.E. Beales of St. Bartholomew's Hospital, London, UK for providing us with human islet cells. This work was supported by a grant from the Juvenile Diabetes Research Foundation International (1-2000-169) and by a grant from the Canadian Diabetes Association (Charles H. Best Fund). A.J. Tingle is a recipient of the Career Investigatorship Award of the British Columbia's Children's Hospital Foundation.

\section{References}

1. Kurrer MO, Pakala SV, Hanson HL, Katz JD (1997) $\beta$-cell apoptosis in T-cell-mediated autoimmune diabetes. Proc Natl Acad Sci USA 94:213-218

2. O'Brien BA, Harmon BV, Cameron DP, Allan DJ (1996) Beta-cell apoptosis is responsible for the development of IDDM in the multiple low-dose streptozotocin model. J Pathol 178:176-181

3. O'Brien BA, Harmon BV, Cameron DP, Allan DJ (1997) Apoptosis is the mode of $\beta$ cell death responsible for the development of IDDM in the nonobese diabetic (NOD) mouse. Diabetes 46:750-757

4. Stephens LA, Thomas HE, Ming L et al. (1999) Tumor necrosis factor-activated cell death pathways in HIT-1 insulinoma cells and primary pancreatic $\beta$ cells. Endocrinology 140:3219-3227

5. Ishizuka N, Yagui K, Tokuyama Y et al. (1999) Tumor necrosis factor alpha signaling pathway and apoptosis in pancreatic $\beta$ cells. Metabolism 48:1485-1492

6. Zumsteg U, Frigerio S, Holländer GA (2000) Nitric oxide production and Fas surface expression mediate two independent pathways of cytokine-induce murine $\beta$ cell damage. Diabetes 49:39-47

7. Delaney CA, Pavlovic D, Hoorens A, Pipeleers DG, Eizirik DL (1997) Cytokines induce deoxyribonucleic acid strand breaks and apoptosis in human pancreatic islet cells. Endocrinology 138:2610-2614

8. Wiley SR, Schooley K, Smolak PJ et al. (1995) Identification and characterization of a new member of the TNF family that induces apoptosis. Immunity 3:673-682

9. Pitti, RM, Marsters SA, Ruppert S, Donahue CJ, Moore A, Ashkenazi A (1996) Induction of apoptosis by Apo-2 ligand, a new member of the tumor necrosis factor cytokine family. J Biol Chem 271:12687-12690

10. Itoh N, Nagata S (1993) A novel protein domain required for apoptosis, Mutational analysis of human Fas antigen. J Biol Chem 268:10932-10937

11. Sheridan JP, Marster SA, Pitti RM et al. (1997) Control of TRAIL-induced apoptosis by a family of signaling and decoy receptors. Science 277:818-821

12. Pan G, O'Rourke K, Chinnaiyan AM et al. (1997) The receptor for the cytotoxic ligand TRAIL. Science 276:111113
13. Pan G, Ni J, Wei YF, Yu G, Gentz R, Dixit VM (1997) An antigonist decoy receptor and a death domain-containing receptor for TRAIL. Science 277:815-818

14. Walczak H, Degli-Esposti MA, Johnson RS et al. (1997) TRAIL-R2 a novel apoptosis-mediating receptor for TRAIL. EMBO J 16:5386-5397

15. MacFarlane M, Ahmad M, Srinivasula SM, FemandesAlnemri T, Cohen GM, Alnemri ES (1997) Identification and molecular cloning of two novel receptor for the cytotoxic ligand TRAIL. J Biol Chem 272:25417-25420

16. Keogh SA, Walczak H, Bouchier-Hayes L, Martin SJ (2000) Failure of Bcl-2 to block cytochrome c redistribution during TRAIL-induced apoptosis. FEBS Lett 471:9398

17. Gura T (1997) How TRAIL kill cancer cells, but not normal cells. Science 277:768-769

18. Strater J, Walczak H, Pukrop T et al. (2002) TRAIL and its receptors in the colonic epithelium: a putative role in the defense of viral infections. Gastroenterology 122:659666

19. Degli-Esposti MA, Smolak PJ, Walczak H et al. (1997) Cloning and characterization of TRAIL-R3, a novel member or the emerging TRAIL receptor family. J Exp Med 186:1165-1170

20. Pan G, Ni J, Yu G, Wei YF, Dixit VM (1998) TRUNDD, a new member of the TRAIL receptor family that antagonizes TRAIL signaling. FEBS Lett 424:41-45

21. Jo M, Kin T-H, Seol D-W et al. (2000) Apoptosis induced in normal human hepatocytes by tumor necrosis factorrelated apoptosis-inducing ligand. Nat Med 6:564-567

22. Nitsch R, Bechmann I, Deisz RA et al. (2000) Human brain-cell death induced by tumor-necrosis-factor-related apoptosis-inducing ligand (TRAIL). Lancet 356:827828

23. Thomas F, Wu J, Contreras JL et al. (2001) A tripartite anoikis-like mechanism causes early isolated islet apoptosis. Surgery 130:333-338

24. Chervonsky AV, Wang Y, Wong S et al. (1997) The role of Fas in autoimmune diabetes. Cell 89:17-24

25. Thomas HE, Darwiche R, Corbett JA, Kay TWH (1999) Evidence that $\beta$ cell death in the nonobese diabetic mouse is Fas independent. J Immunol 163:1562-1569

26. Wang J, Lo JC, Foster A et al. (2001) The regulation of T cell homeostasis and autoimmunity by $\mathrm{T}$ cell-derived LIGHT. J Clini Invest 108:1771-1780

27. Jeremias I, Herr I, Boehler T, Debatin KM (1998) TRAIL/Apo-2-ligand-induced apoptosis in human T cells. Eur J Immunol 28:143-152

28. Wendling U, Walczak H, Dörr J et al. (2000) Expression of TRAIL receptors in human autoreactive and foreign antigen-specific T cells. Cell Death Differentiation 7:637-644

29. Vives M, Soldevila G, Alcalde L, Lorenzo C, Somoza N, Pujol-Borrell R (1991) Adhesion molecules in human islet $\beta$-cells: De novo induction of ICAM-1 but not LFA-3. Diabetes 40:1382-1390

30. Baroni MG, Cavallo MG, Mark M, Monetini L, Stoehrer B, Pozzilli P (1999) Beta-cell gene expression and functional characterization of the human insulinoma cell line CM. J Endocrinol 161:59-68

31. Ou D, Chong P, Tripet B, Gillam S (1992) Analysis of T- and B-cell epitopes of capsid protein of rubella virus by using synthetic peptides. J Virol 66:1674-1681

32. Ou D, Jonsen LA, Metzger DL, Gillam S, Tingle AJ (2000) Crossreactive rubella virus and glutamic acid decarboxylase (65 and 67) protein determinants recognized by $\mathrm{T}$ cells of patients with Type I diabetes. Diabetologia 43:750763 
33. Ou D, Mitchell LA, Domeier ME et al. (1996) Characterization of HLA restrictive elements of rubella virus-specific cytotoxic T-cell clone: Influence of HLA-DR4 $\beta$ chain residue 74 polymorphism on $\mathrm{Ag}$ peptide-T cell interaction. Int Immunol 8:1577-1586

34. Ou D, Jonsen LA, Metzger DL, Tingle AJ (1999) CD4+ and $\mathrm{CD}^{+} \mathrm{T}$ cell clones from congenital rubella syndrome patients with IDDM recognized overlapping GAD65 protein epitopes: Implications for HLA class I and II allelic linkage to disease susceptibility. Hum Immunol 60:652664

35. Ou D, Mitchell LA, Décarie D, Gillam S, Tingle AJ (1997) Characterization of overlapping $\mathrm{CD}^{+}$and $\mathrm{CD} 4{ }^{+}$T-cell epitope on rubella capsid protein. Virology 235:286-291

36. Ashkenszi A, Dixit VM (1999) Apoptosis control by death and decoy receptors. Curr Opin Cell Biol 11:255-260

37. Bretz JD, Baker R Jr (2000) Apoptosis and autoimmune thyroid disease: following a TRAIL to thyroid destruction? Clin Endocrinol 55:1-11

38. Yeh WC, Pompa JL, McCurrach ME et al. (1998) FADD: Essential for embryo development and signaling from some, but not all, inducers of apoptosis. Science 279:19541958

39. Kuang AA, Diehl GE, Zhang J, Winoto A (2000) FADD is required for DR4- and DR5-mediated apoptosis. J Biol Chem 275:25065-25068

40. Zhang XD, Nguyen T, Thomas WD, Sanders JE, Hersey P (2000) Mechanisms of resistance of normal cells to TRAIL induced apoptosis vary between different cell types. FEBS Lett 482:193-199

41. Mongkolsapaya J, Cowper AE, Xu XN et al. (1998) Lymphocyte inhibitor of TRAIL (TNF-related apoptosis-inducing ligand): a new receptor protecting lymphocytes from the death ligand TRAIL. J Immunol 160:3-6

42. Schneider P, Bodmer JL, Thome M, Hofmann K, Holler N, Tschopp J (1997) Characterization of two receptors for TRAIL. FEBS Lett 416:329-334

43. Marsters SA, Sheridan JP, Pitti RM et al. (1997) A novel receptor for Apo2L/TRAIL contains a truncated death domain. Curr Biol 7:1003-1006

44. Degli-Esposti MA, Dougall WC, Smolak PJ, Waugh JY, Smith CA, Goodwin RG (1997) The novel receptor TRAIL-R4 induces NF-kappaB and protects against TRAIL-mediated apoptosis, yet retains an incomplete death domain. Immunity 7:813-820

45. Griffith TS, Lynch DH (1998) TRAIL: a molecule with multiple receptors and control mechanisms. Curr Opin Immunol 10:559-563
46. Deveraux QL, Reed JC (1999) IAP family proteinssuppressors of apoptosis. Genes Dev 13:239-252

47. Wang CY, Mayo MW, Korneluk RG, Goeddel DV, Baldwin AB Jr (1998) NF-kappaB antiapoptosis: induction of TRAF1 and TRAF2 and c-IAP1 and c-IAP2 to suppress caspase- 8 activation. Science 281:1680-1683

48. Schneider P, Thome M, Burns K et al. (1997) TRAIL receptors 1 (DR4) and 2 (DR5) signal FADD-dependent apoptosis and activate NF-kappaB. Immunity 7:831-836

49. Screaton GR, Mongkolsapaya J, Xu X-N, Cowper AE, McMichael AJ, Bell JI (1997) TRICK2, a new alternatively spliced receptor that transduces the cytotoxic signal from TRAIL. Curr Biol 7:693-696

50. Emery JG, McDonnell P, Burke MB et al. (1998) Osteoprotegerin is a receptor for the cytotoxic ligand TRAIL. J Biol Chem 273:14363-14367

51. Song K, Chen Y, Göke R et al. (2000) Tumor necrosis factor-related apoptosis-inducing ligand (TRAIL) is an inhibitor of autoimmune inflammation and cell cycle progression. J Exp Med 191:1095-1103

52. Bretz JD, Rymaszewski M, Arscott PL et al. (1999) TRAIL death pathway expression and induction in thyroid follicular cells. J Biol Chem 274:23627-23632

53. Santamaria P (2001) Effector lymphocytes in autoimmunity. Curr Opin Immunol 13:663-669

54. Martinez-Lorenzo MJ, Anel A, Gamen S et al. (1999) Activated human $\mathrm{T}$ cells release bioactive Fas ligand and APO2 ligand in microvesicles. J immunol 163:12741281

55. Kayagaki N, Yamaguchi N, Nakayama M et al. (1999) Involvement of TNF-related apoptosis-inducing ligand in human $\mathrm{CD} 4+\mathrm{T}$ cell-mediated cytotoxicity. J Immunol 162:2639-2647

56. Clarke P, Meinitzer SM, Gibson S et al. (2000) Reovirusinduced apoptosis is mediated by TRAIL. J Virol 74:81358139

57. Katsikis PD, Garcia-Ojeda ME, Torres-Roca JF, Tijoe IM, Smith CA, Herzenberg LA (1997) Interleukin-1 $\beta$ converting enzyme-like protease involvement in Fas-induced and activation-induced peripheral blood $\mathrm{T}$ cells apoptosis in HIV infection. TNF-related apoptosis-inducing ligand can mediate activation-induced $\mathrm{T}$ cell death in HIV infection. J Exp Med 186:1365-1372

58. Zhang XD, Franco A, Myers K, Gray C, Nguyen T, Hersey P (1999) Relation of TNF-related apoptosis-inducing ligand (TRAIL) receptor and FLICE-inhibitory protein expression to TRAIL-induced apoptosis of melanoma. Cancer Res 59:2747-2753 